\title{
Hgrizons
}

\section{Infant Feeding Counsel ing Within Kenyan and Zambian PMTCT Services: How Well Does It Promote Good Feeding Practices?}

nfant feeding counseling is an important intervention for the prevention of mother-to-child transmission (PM TCT) of HIV. M ore than one-third of H IV transmission to infants occurs through breastfeeding, and up to 20 percent of infants born to H IV-infected mothers acquire the virus from breast milk in countries where extended breastfeeding of children is the norm (WH O 2001). The World $\mathrm{H}$ ealth O rganization advises that H IV-positive mothers should be offered nondirective counseling on various infant feeding options that are feasible, affordable, safe, sustainable, and effective in the local context.

The H orizons Program collaborated with NARESA in Kenya, the MTCT Working Group in Zambia, and UNICEF to examine the implementation of infant feeding counseling as part of a comprehensive study in each country to document the acceptability, operational barriers, cost, and impact of pilot PM TCT services. The major research activities included tracking the utilization of various services; following a cohort of clinic users for 12 to 18 months to determine outcomes of service utilization on knowledge, practices, and rates of mother-to-child H IV transmission; observation of the quality of care delivered by providers; and an economic analysis of the PM TCT program. In addition,

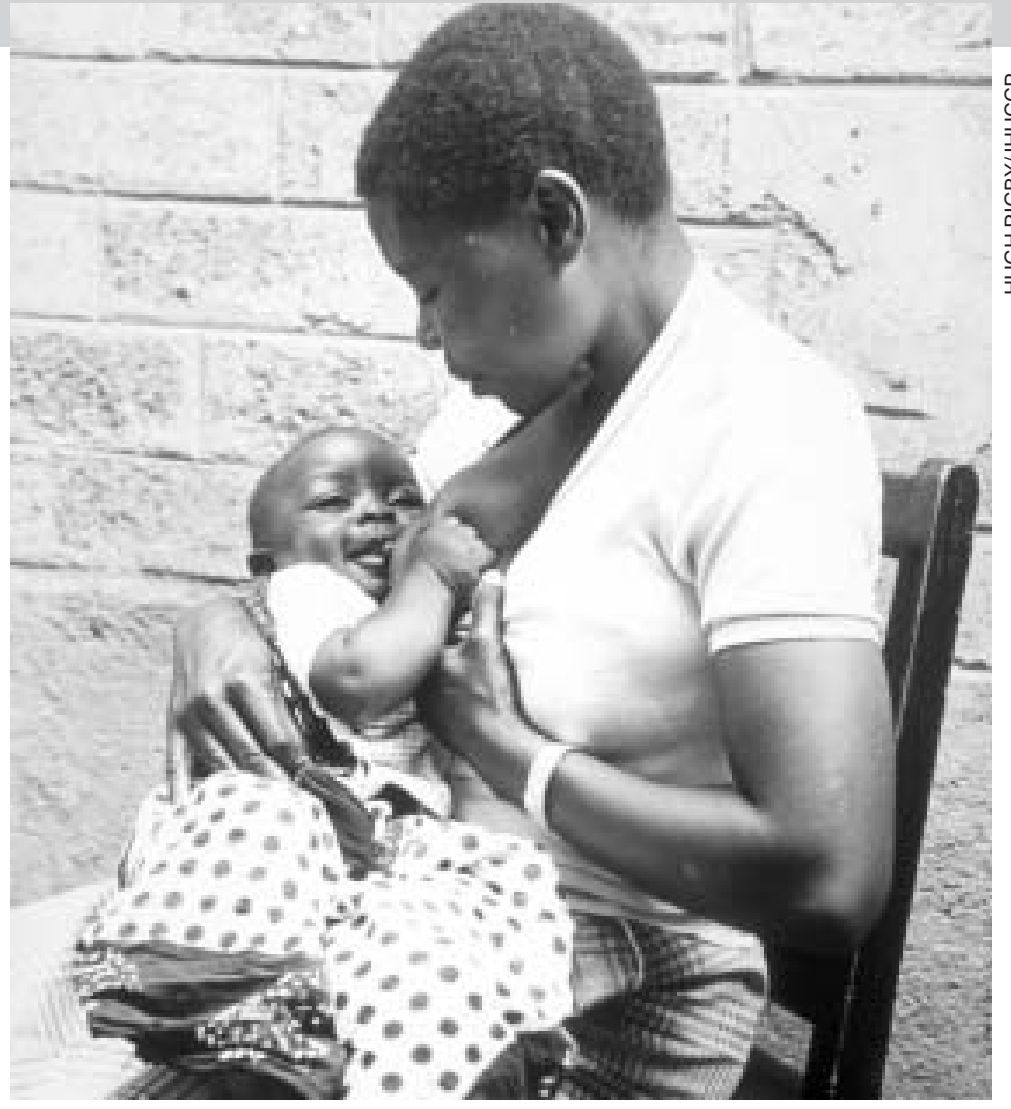

a midterm rapid assessment of the intervention at the Zambia PM TCT sites was undertaken as part of a global evaluation of U N-supported pilot PM TCT services (see Rutenberg et al. 2003). These studies contribute critically needed information for informing policy and program design and for documenting best practices for PM TCT.

A particularly challenging component of PM TCT services is providing counseling that promotes good infant feeding practices. This summary presents key findings from the 
Kenya and Zambia studies on the content of counseling, provider attitudes about infant feeding options, and the extent to which actual infant feeding practice by mothers is consistent with recommended practice.

\section{Methods}

Researchers looked at the infant feeding practices of mother and infant pairs who received newly introduced PM TCT services at Chipata C linic in Lusaka, Zambia, and Karatina and H oma Bay district hospitals in Kenya. Chipata C linic serves a densely populated, poor, peri-urban settlement in L usaka, where service statistics show that one out of four antenatal clients is H IV-positive. At H oma Bay D istrict H ospital, which serves a very poor area in western Kenya, HIV prevalence among antenatal clients is about 33 percent, one of the highest in Kenya. In contrast, less than 10 percent of pregnant women seen at the D istrict $\mathrm{H}$ ospital in Karatina, a town in the relatively prosperous central highlands about two hours north of Nairobi, are H IV-positive.

$M$ idwife/ counselors administered questionnaires to H IV-positive and H IV-negative women. In Zambia, 422, 374, and 322 women were interviewed, respectively, at one week, three months, and six months postpartum about their infant feeding practices. Women were interviewed at six weeks, three months, and six months postpartum in Kenya; 380, 313, and 286 women in $\mathrm{H}$ oma Bay and 588, 412, and 339 women in Karatina were interviewed, respectively, at the three points in time. A pre-intervention comparison group of 264 women in Lusaka, 329 in H oma Bay, and 328 in Karatina were interviewed at three months (Zambia) and six weeks (Kenya) postpartum.

$D$ ata from the rapid assessment of $U \mathrm{~N}$-supported PM TCT services in Zambia reveal providers' approach to and actual delivery of infant feeding counseling. Interviews were conducted at all six pilot sites with 35 clinical and counseling providers who conduct infant feeding counseling, and with 67 women who were either pregnant ( $>20$ weeks gestation) or had an infant less than six months old and re-ceived infant feeding counseling on the day of the assessment. Study staff also observed 42 infant feeding counseling sessions and noted the content, using a checklist.

\section{Key Findings}

Infant feeding counselors explore some but not all key issues with clients.

When speaking to an H IV-positive woman about infant feeding, PM TCT providers in Zambia reported their role as one of giving information, encouragement, and support, and helping women make a decision about an infant feeding option. This was observed to be the case in most counseling sessions. In slightly over half (26/42) of sessions observed, the providers adequately explored (and in 12 observations "somewhat" explored) the feasibility and acceptability of various feeding options. With one exception, every provider made suggestions rather than commands about infant feeding options. M ost (87 percent) clients were married or living with a partner, and providers directly addressed partner involvement in infant feeding decisions in threequarters of the sessions.

But in the majority of sessions, counselors did not ascertain the clients' specific circumstances regarding household resources, which is necessary to help women consider their ability to implement various feeding choices. For example, while formula was discussed in 38 of the 42 sessions, in only 10 of the 42 sessions did providers inquire whether the mother had money to buy infant formula. Whether the client had access to adequate supplies of water and fuel was asked in only 6 of 42 sessions. D iscussions about disclosing H IV status to partners were observed in only 7 of the 42 sessions, and in only 5 of the 42 was the client asked whether she had disclosed her H IV status to other family members or close friends. 


\section{Infant Feeding Guidelines in Kenya and Zambia}

L ocal guidelines developed for PM TCT in Kenya and $Z$ ambia recommend that pregnant mothers be informed about the risks of mother-to-child transmission during infant feeding and that infant feeding options be discussed.

In Kenya, women who receive a negative HIV test result and women of unknown status are recommended to breastfeed their infant exclusively. Women who receive an H IV-positive test result are counseled about the risks of breast milk transmission of HIV and informed of three optimal choices: exclusive breastfeeding, replacement feeding with formula, and replacement feeding with modified cow's milk. H IVpositive women who choose to breastfeed are supported with appropriate information and skills counseling on good breastfeeding techniques to enable exclusive breastfeeding and to shorten the duration of breastfeeding. H IV-positive mothers who choose not to breastfeed receive education and support on how to prepare and give their infant the replacement feed, as well as six months supply of infant formula.

In the Zambian PM TCT program, HIV-negative women and those of unknown status are also encouraged to exclusively breastfeed for six months and continue breastfeeding up to 24 months. The program recommends three infant feeding options to H IV-positive women: (1) exclusive breastfeeding for six months with abrupt cessation, (2) exclusive breastfeeding for three to four months with abrupt cessation, and (3) exclusive formula feeding, with infant formula supplies and education in its preparation provided by the program to the mother.

Similarly, in response to the question, "What are your opinions about H IVpositive women who do not breastfeed?" 28 providers had a positive opinion that the woman was doing the "right thing," one was negative, and six were neutral. Finally, in response to a question on whether they thought there was one best infant feeding method for H IV-positive women, 23 providers replied formula, one replied exclusive breastfeeding for six months, and 11 said there was no best method, because each had advantages and disadvantages. Providers' opinions about breastfeeding by HIV-positive women and the optimal choice of feeding method for their infants was unrelated to whether he/ she had received training on infant feeding counseling.

\section{Clients express satisfaction with counselors and feel they've been given choices.}

Clients see the counselors as providing convincing, sound, and comforting information about what the optimal choice is and are helping women feel they have made a good decision (even if they have not made much of a decision but rather followed the counselor's lead). About half (33/67) of women interviewed felt that the infant feeding

\section{$M$ any counselors have biases about infant feeding choices for HIV-positive women.}

$D$ ata from interviews with providers in Zambia reveal that most providers showed a bias toward infant formula as the preferred infant feeding method for HIV-positive women. For example, when asked, "What are your opinions about HIV-positive women who breastfeed?" five providers gave a positive opinion, 20 were negative (mostly about the risk of infecting the child through breast milk), and seven were neutral and said that it was the woman's choice (three voiced difficulties about the implementation of this choice rather than whether it is appropriate). counseling session had helped them decide how to feed their babies. Twenty-six of the respondents said they had chosen formula feeding, 24 had decided to breastfeed (with about half specifically mentioning exclusive breastfeeding), and five were undecided (the choices of 12 were unknown). O nly 19/ 67 reported that they felt a particular option was being promoted. Instead most felt as this client did:

"[The counseling] did help me decide because I now know advantages and disadvantages [of the infant feeding options]." 
PM TCT programs in study sites had mixed success in improving infant feeding practices.

PM TCT infant feeding guidelines recommend exclusive breastfeeding for mothers who are HIV-negative or do not know their H IV statusthe majority of women-and either replacement feeding or exclusive breastfeeding for H IVpositive mothers. Successful PM TCT programs should thus be able to show that increasing numbers of women are practicing exclusive breastfeeding, with a proportion of H IV-positive women using replacement feeding, and little use overall of the more dangerous practice of mixed feeding. The extent to which PM TCT programs have improved infant feeding practice were examined by comparing practices among women who used the $\mathrm{MCH}$ services before the introduction of PM TCT services (the comparison group) and women in the cohort studies who were exposed to PM TCT information and counseling. Infant feeding practice based on a 24-hour recall for mothers of three-month-old infants in

Zambia and six-week-old infants in Kenya are shown in Table 1.

The results show that a slightly larger proportion of women who were exposed to PM TCT services reported using replacement feeding, which was expected because infant formula was offered to H IV-infected mothers. H owever, there is little evidence of a shift from the undesirable practice of mixed feeding to the safer practice of exclusive breastfeeding; a large proportion-about onethird of women in Lusaka and 70 percent of women in the two sites in Kenya-continue to practice mixed feeding. In fact, there was a significant decline in exclusive breastfeeding at one site (Karatina) in Kenya.

In contrast, a study conducted in N dola, Zambia, by $\mathrm{H}$ orizons and its partners ${ }^{1}$ of the $\mathrm{N}$ dola Demonstration Project (NDP) showed that intensive efforts to improve infant feeding counseling as part of PM TCT programs can help pregnant women make informed choices to protect their health and the health of their infants (see page 5).

H IV-negative mothers were somewhat more likely than HIV-positive women to exclusively breastfeed, although they also tended to start mixed feeding earlier.

$\mathrm{H}$ igh rates of exclusive breastfeeding of young babies were seen in Lusaka, where more than 90 percent of H IV-negative and 56 percent of HIVpositive women in the study exclusively breastfed in the first week postpartum (see Figure 1, page 6). H owever, by three months, only 56 percent of H IV-negative and 40 percent of H IV-positive

Table 1 Comparison of feeding practiced in $\mathbf{2 4}$ hours before interview between women of all HIV status in baseline and in intervention group, by selected age of infant and site

\begin{tabular}{lcc|cc|cc}
\hline & \multicolumn{2}{c|}{ Lusaka } & \multicolumn{2}{c|}{ Karatina } & \multicolumn{2}{c}{ Homa Bay } \\
& $\begin{array}{c}\text { Comparison } \\
\mathbf{3} \text { months } \\
\mathbf{n = 2 6 4} \\
\%\end{array}$ & $\begin{array}{c}\text { Intervention } \\
\mathbf{3} \text { months } \\
\mathbf{n}=\mathbf{3 7 4} \\
\%\end{array}$ & $\begin{array}{c}\text { Comparison } \\
\mathbf{6} \text { weeks } \\
\mathbf{n = 3 2 8} \\
\%\end{array}$ & $\begin{array}{c}\text { Intervention } \\
\mathbf{6} \text { weeks } \\
\mathbf{n = 5 8} \\
\%\end{array}$ & $\begin{array}{c}\text { Comparison } \\
\mathbf{6} \text { weeks } \\
\mathbf{n = 3 2 9} \\
\%\end{array}$ & $\begin{array}{c}\text { Intervention } \\
\mathbf{6} \text { weeks } \\
\mathbf{n}=\mathbf{3 8 0} \\
\%\end{array}$ \\
\hline $\begin{array}{l}\text { Exclusive } \\
\text { breastfeeding }\end{array}$ & 59.8 & 53.4 & 34.1 & 27.0 & 21.7 & 25.8 \\
$\begin{array}{l}\text { Mixed feeding } \\
\text { Replacement }\end{array}$ & 38.4 & 36.8 & 65.6 & 68.5 & 76.5 & 70.3 \\
feeding & 2.4 & 9.8 & 0.3 & 4.4 & 1.9 & 4.0 \\
Total & 100.0 & 100.0 & 100.0 & 100.0 & 100.0 & 100.0
\end{tabular}




\section{HIV and Infant Feeding Intervention Strengthens Exclusive Breastfeeding Rates}

In M ay 2000, a package of PM TCT services was introduced into routine antenatal and postnatal consultations at six M CH clinics in N dola, Zambia, with a particular focus on infant feeding guidance and VCT. (No antiretrovirals were available at this time.) All pregnant women and mothers attending routine clinic consultations received context-specific infant feeding information based on local assessments. A counselor guided each woman through the choices, encouraging her to evaluate the relative risks and benefits of each feeding option. A H orizons-led research team measured changes in knowledge, attitudes, and practices about infant feeding and other topics among samples of pregnant women and mothers of young children.

By the end of the study period, more women became aware that $\mathrm{HIV}$ can be transmitted during breastfeeding, and most knew that they could reduce the risk through early weaning or replacement feeding. Yet, contrary to concerns that discussing H IV risk might erode good breastfeeding practice, most women reported following program guidelines in choosing to exclusively breastfeed, even though more than 85 percent had not been tested. Following the intervention, the percentage of mothers of unknown H IV status with infants six months old or younger reporting that they were exclusively breastfeeding rose from 57 percent to 70 percent, and fewer mothers reported mixed feeding. M ore than 70 percent of health workers interviewed said that they felt technically competent to provide infant feeding counseling, and observations confirmed that they were increasingly integrating infant feeding counseling into $\mathrm{ANC} / \mathrm{MCH}$ sessions.

The study showed that the program's conscientious reinforcement of a long history of breastfeeding promotion in $\mathrm{N}$ dola, including community-based education and mobilization, helped to increase exclusive breastfeeding rates even further. Another important factor was the intensive and ongoing training of clinic- and community-based health workers, combined with information provided to mothers about PM TCT and infant feeding.

Source: Kalibala, S. et al. 2003. Empowering Communities to R espond to HIV/ AID S: N dola D emonstration Project on $M$ aternal and Child $\mathrm{H}$ ealth: O perations Research Final Report. Population Council: Washington, DC.

http:/ / www.popcouncil.org/ pdfs/ horizons/ ndolafnl.pdf

women were exclusively breastfeeding, and by six months few children of either H IV-negative or H IV-positive mothers were still being exclusively breastfed.

M ost infants at three and six months of age in L usaka were given mixed feeding: both breast milk and other foods. H IV-negative women were more likely than HIV-positive women to mix breastfeeding and other feeds, with four out of ten HIV-negative women giving mixed feeding by the third month of life and nearly 90 percent by six months (see Figure 2, page 6). O nequarter of HIV-positive women were practicing mixed feeding at three months and just over half at six months.

Exclusive breastfeeding rates were lower in Kenya, where slightly more than one-quarter of H IV-negative and 15 to 25 percent of H IVpositive women were exclusively breastfeeding their infants at six weeks of age (see Table 2). $M$ ixed feeding was quite common in $\mathrm{H}$ oma Bay, with 71 and 64 percent of H IV-negative and H IV-positive women, respectively, practicing mixed feeding for six-week-old infants. The lowest use of mixed feeding for young infants was among HIV-positive women in Karatina. The 
Figure 1 Percent exclusively breastfeeding, by maternal HIV status and age of infant, Lusaka, Zambia

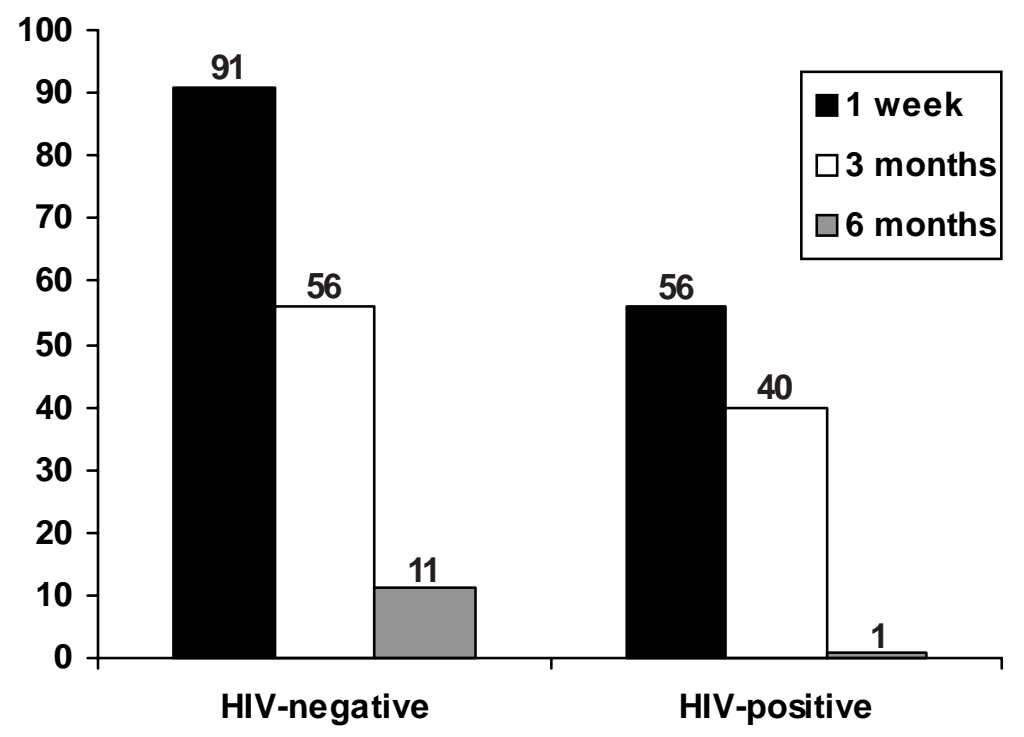

Note: Based on 24-hour recall

most common feeding practice of H IV-positive women in this site was the use of local foods to completely replace breast milk. M ost H IVnegative mothers in Kenya ceased exclusive breastfeeding when their infants were between the ages of three and six months and offered $a$ mix of breast milk and other foods. H IV-positive mothers in Karatina also stopped exclusive breastfeeding at this age but were likely to wean their infants, while most H IVpositive mothers in $\mathrm{H}$ oma Bay had stopped exclusive breastfeeding before their children reached three months of age but continued to offer breast milk along with other foods.

\section{A minority of HIV-positive women chose formula feeding.}

At the three study sites, H I V-positive women in Lusaka and Karatina used formula more often. The highest use of formula was among H IV-positive women in Lusaka, where 17 percent reported exclusively formula feeding their infants at one week postpartum and 11 percent at three months postpartum. Comparable levels were found in Karatina, with 9 percent reporting exclusively formula feeding their infants at six weeks postpartum and 13 percent at three months postpartum.

Formula was least common in H oma Bay, the most impoverished and most HIVaffected of the three sites, with only 3 and 6 percent of H IV-positive women reporting exclusively using infant formula at the sixweek and three-month postpartum visits, respectively.

\section{M any H IV-positive women did not follow the PMTCT program's recommendation to wean early.}

Though program guidelines recommend a shortened duration of four to six months of breastfeeding for HIV-positive women, a significant number of H IV-positive women at all sites continued to breastfeed their infants at six months of age (see Figure 2 and Table 2). M ore than half of the infants of H IV-positive women in L usaka and nearly 80 percent of the infants of H IV-positive women in H oma Bay were still receiving breast milk at six months of age. The figure was lower in Karatina, where more than 60
Figure 2 Percent practicing mixed feeding, by maternal HIV status and age of infant, Lusaka, Zambia

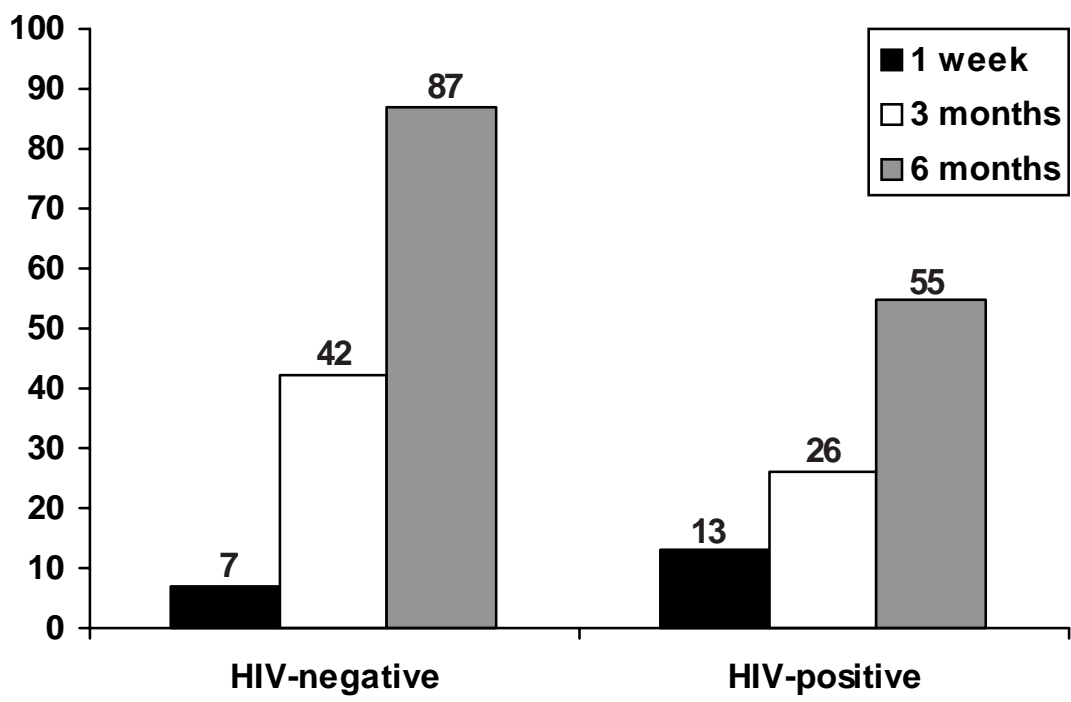

Note: Based on 24-hour recall 
percent of infants had been weaned by the age of six months but where a substantial minority was still receiving breast milk.

There is no evidence of "spillover" of the practice of replacement feeding to women of unknown HIV status.

Some observers have expressed concern that PM TCT programs that discuss replacement feeding for HIV-positive mothers may inadvertently cause other mothers who do not know their H IV status to avoid breastfeeding. This evaluation found little evidence of this "spillover" effect. In Kenya, less than 2 percent of women of unknown status in both Karatina and $\mathrm{H}$ oma Bay report exclusive use of infant formula or other replacement feeds (see Table 2). This is similar to the very low proportion (less than 1 percent) of H IV-negative women at both sites who use replacement feeds. Thus, women of unknown HIV status living in areas with a PM TCT program are not disproportionately using replacement feeds.

\section{Recommendations}

Infant feeding continues to be a particularly challenging component of PM TCT programs. In such settings as Kenya and Zambia, where half of all women breastfeed their children for 18 months and longer, a significant proportion of H IV transmission-up to 40 percent-can occur through breastfeeding. Clearly, PM TCT programs need to intensify their efforts to provide mothers with infant feeding counseling and support.

The results of these operations research and evaluation studies suggest several actions

Table 2 Feeding practiced in 24 hours before interview for selected ages of infant, by maternal HIV status at Kenyan PMTCT sites

\begin{tabular}{|c|c|c|c|c|c|c|}
\hline & \multicolumn{3}{|c|}{ Karatina } & \multicolumn{3}{|c|}{ Homa Bay } \\
\hline & HIV- & $\mathrm{HIV+}$ & Unknown & HIV- & HIV+ & Unknown \\
\hline \multicolumn{7}{|l|}{$\begin{array}{l}\text { Exclusive } \\
\text { breastfeeding }\end{array}$} \\
\hline 6 weeks & 28.6 & 14.9 & 23.6 & 28.1 & 22.3 & 24.5 \\
\hline 3 months & 23.9 & 12.9 & 18.1 & 21.4 & 9.7 & 14.7 \\
\hline 6 months & 4.6 & 2.7 & 6.2 & 5.5 & 4.8 & 0.0 \\
\hline \multicolumn{7}{|l|}{ Mixed feeding } \\
\hline 6 weeks & 70.9 & 34.0 & 73.7 & 71.4 & 63.8 & 74.5 \\
\hline 3 months & 75.7 & 25.8 & 80.6 & 78.6 & 69.4 & 85.3 \\
\hline 6 months & 94.5 & 35.1 & 92.3 & 93.9 & 74.2 & 98.3 \\
\hline \multicolumn{7}{|c|}{$\begin{array}{l}\text { Exclusive formula } \\
\text { feeding }\end{array}$} \\
\hline 6 weeks & 0 & 8.5 & 0 & 0 & 3.2 & 0 \\
\hline 3 months & 0 & 12.9 & 0 & 0 & 5.6 & 0 \\
\hline 6 months & 0 & 2.7 & 0 & 0 & 0.0 & 0 \\
\hline \multicolumn{7}{|c|}{$\begin{array}{l}\text { Complementary } \\
\text { feeding only } \\
\text { (no breastfeeding) }\end{array}$} \\
\hline 6 weeks & 0.5 & 42.6 & 0.0 & 0.5 & 10.6 & 1.1 \\
\hline 3 months & 0.3 & 48.4 & 0.0 & 0.0 & 15.3 & 0.0 \\
\hline 6 months & 0.8 & 59.5 & 1.5 & 0.6 & 21.0 & 1.7 \\
\hline
\end{tabular}


providers and program managers should take to ensure that women are providing optimal nutrition to their infants while safeguarding them from HIV:

- Reinforce the importance of exclusive breastfeeding when breastfeeding is the chosen option.

- Extend infant feeding counseling beyond antenatal care visits. Follow up in the postpartum period, when women are making decisions about how to feed their infants and grappling with the implementation of their choices.

- Identify, test, and promote strategies for helping HIV-positive women wean their infants by four to six months of age. Given the significance of breast milk transmission of $\mathrm{HIV}$, there is a need for policymakers to explore options for providing acceptable and safe replacement feeds.

- Foster peer support in the community by facilitating community-based support groups and by training and supporting peer counselors to create an environment where women who choose to exclusively breastfeed or use infant formula will not be stigmatized.

${ }^{1}$ The $\mathrm{N}$ dola $\mathrm{D}$ istrict $\mathrm{H}$ ealth $\mathrm{M}$ anagement Team (DH M T), LIN KAGES, Zambia's N ational Food and N utrition Commission, $\mathrm{H}$ ope $\mathrm{H}$ umana, and the Zambia I ntegrated $\mathrm{H}$ ealth Project.

\section{References}

Rutenberg, N. et al. 2003. Evaluation of U nited $N$ ations-supported pilot projects for the prevention of mother-to-child transmission of HIV. N ew York: U NICEF and Population Council. http:/ / www.popcouncil.org/ pdfs/ horizons/ pmtctunicefevalovrvw.pdf

WH O. 2001. Prevention of mother to child transmission of HIV: selection and use of nevirapine. Technical notes. Geneva: World $\mathrm{H}$ ealth O rganization.

D ecember 2003

Study investigators include $M$ argaret Siwale and Chipepo Kankasa of the MTCT Working Group in Zambia; Ruth $N$ duati, Dorothy $M$ bori $N$ gacha, and Jennifer O yieke of NARESA in Kenya; N aomi Rutenberg and Scott Geibel of H orizons/ Population Council; and Sam Kalibala of the International AIDS Vaccine Initiative (formerly of Horizons).

Suggested citation: Rutenberg, N . et al. 2003. "Infant Feeding Counseling Within Kenyan and Zambian PM TCT Services: H ow Well Does It Promote Good Feeding Practices?" H orizons Research Summary. Population Council: Washington, DC.

Photo courtesy of Photoshare, a service of the INFO Project.

\section{Hqrizons}

Population Council/ Horizons

Communications Unit

4301 Connecticut Avenue, NW

Suite 280

Washington, DC 20008
Population Council

Tel: $202-237-9400$

Fax: 202-237-8410 horizons@pcdc.org www. popcouncil.org/ horizons
UsaID This publication was made possible through support provided by the Global Bureau of Health/HIV-AIDS, U.S. Agency for International Development, under the terms of Award No. HRN-A-00-97-00012-00. The opinions expressed herein are those of the authors and do not necessarily reflect the views of the U.S. Agency for International Development. 